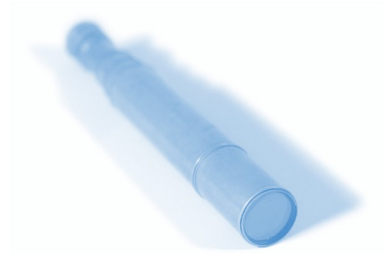

\author{
Nancy El-Farargy \\ Centre of Science \\ James Watt College of \\ Further and Higher \\ Education \\ Finnart Campus \\ Greenock \\ PA16 8HF \\ nelfarargy@ \\ jameswatt.ac.uk
}

\title{
Epistemological beliefs and intellectual development in the physical sciences
}

\begin{abstract}
Much research has been documented on the stage of students' intellectual and epistemological development during their studies and upon course completion. To a large extent, the literature suggests that promoting students through the intellectual framework is a desirable feat. Indeed, students graduating from university at the more developed stages of intellectual and epistemological sophistication are better equipped to synthesise, evaluate, organise and cross reference knowledge into different domains.

In this review, modes of epistemological beliefs will be discussed as sources of valuable information to departments about the quality and nature of students' perceptions of learning and teaching. The results of recent research in epistemological and intellectual development will also be discussed; this perhaps being a mechanism to inform learning and teaching practices within the physical sciences.
\end{abstract}

\section{Epistemological and Intellectual Development}

Epistemology refers to the justification, nature, sources and evaluation of knowledge ${ }^{1,2,3}$. It has been reported that epistemological and cognitive sophistication is positively related to skills such as critical thinking, self regulation ${ }^{4}$, ability to communicate ideas and to learn in collaboration ${ }^{5}$. Indeed, physical scientists may be viewed as professional epistemologists in that they use prior knowledge to generate knowledge through explicit and reliable methods. How students construct knowledge during their university years is important for their future careers where the ability to integrate, evaluate and apply scientific knowledge is required.

\section{How students construct knowledge during their university years is} important for their future careers where the ability to integrate, evaluate and apply scientific knowledge is required.
The investigation of students' perceptions of learning, teaching and epistemological beliefs in the sciences has been widely researched because of their influences on learning, goal orientation and use of cognitive strategies ${ }^{6,7,8}$. This has been a relatively active area of research ${ }^{8,9}$ and can be traced back to the original intellectual and developmental work of William Perry in $1968^{10}$. His theory offered an unfolding of students' views on development, learning, authority and the nature of knowledge as they progress through their university years. A scheme that conceptualised the development of higher cognitive skills was formed (Table 1), providing a specified hierarchal sequence of human experience from basic duality to identity, commitment and maturation (see also the work by Bhattacharyya ${ }^{11}$ ). The intermediary stages are typified by dissonance where individuals encounter and recognise imperfections and fallibilities in 'authorities' (e.g. models, textbooks etc).

Perry argued that the most significant intellectual shifts occur during university, when students are confronted with and expected to reconcile multiple authoritative sources. Cognitively, students become active generators of their own knowledge and become socially aware of their commitments and identities.

Perry reported that few students enter university at the basic dualistic stage and in his study; he found that over $70 \%$ of students leave university having attained levels of commitment, exemplified by stages 7 and 8 . Perry also suggested that individuals may depart from the main line of development by suspending, nullifying or even reversing the process of growth. 


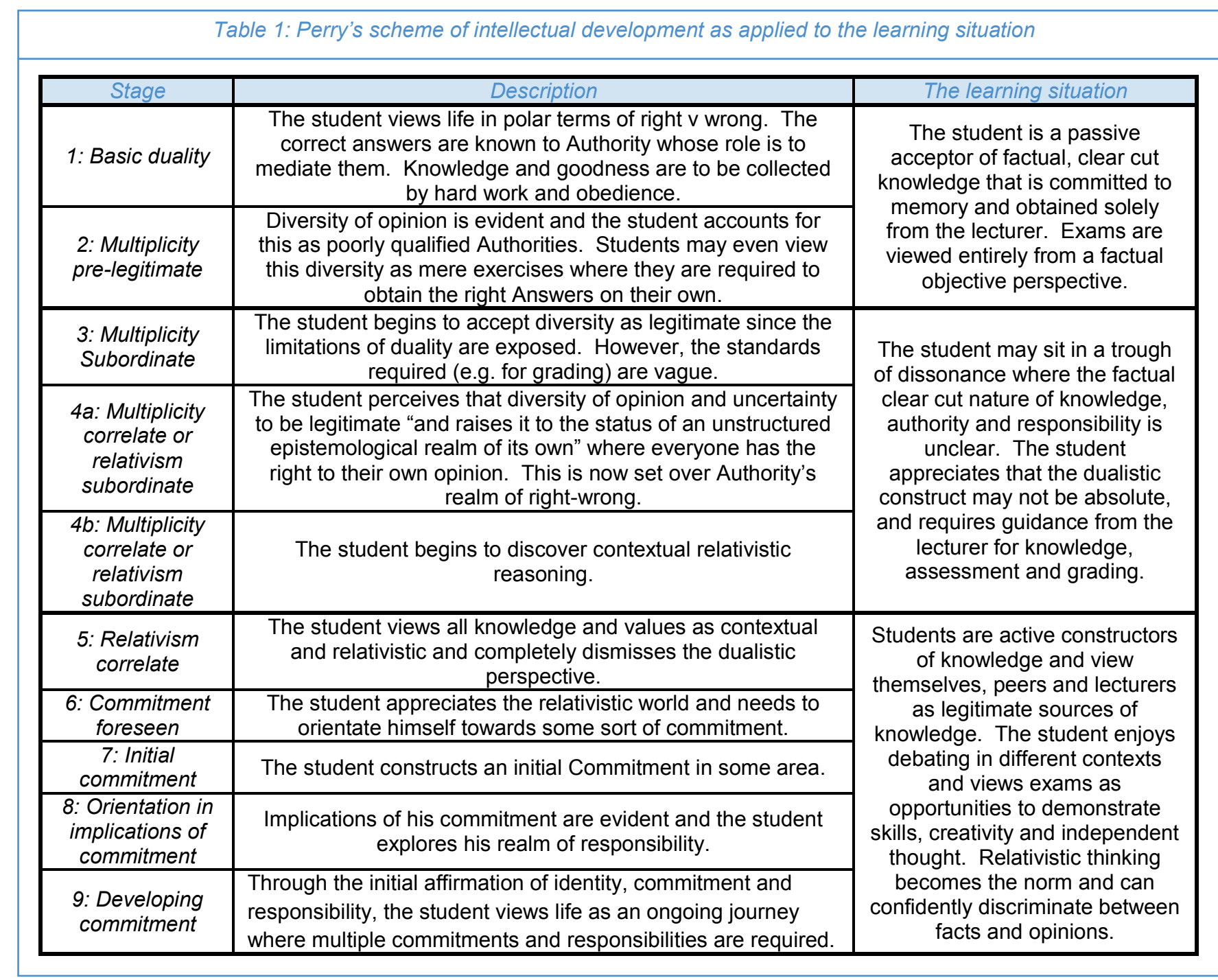

Recently, much emphasis is placed upon how university experiences affect students ${ }^{12}$, and Perry's theory has remained the cornerstone and guiding framework of many research studies of student development, throughout their education and onwards throughout their careers.

Because of limitations in the original scheme, other similar theories ${ }^{13,14,15,16}$ have since been reported and most are concerned with the development of individuals' beliefs ranging from the stance of black and white absolute thinking to a sophisticated, evolving and rationally evaluated viewpoint of the world.

\section{Literature review}

How students approach their physics learning has been reported to be related to their perceptions of knowledge and the nature of physics ${ }^{17,18,19,20}$. For example, May and Etkina ${ }^{18}$ have shown that through the use of students' submission of weekly reports, those students who showed higher conceptual gains were more likely to mention more developed epistemological learning activities, such as learning formulae with conceptual understanding with a lesser reliance on authority. Nussbaum, Sinatra and Poliquin ${ }^{21}$ have reported that those students classified as evaluatists interacted with knowledge more critically and were better at solving physics problems than those students who were classified as multiplists. Multiplists were less critical of misconceptions and inconsistencies in relation to problems in air and gravity. Richter and Schmid ${ }^{4}$ showed that epistemological attitudes and beliefs affect self regulated learning. Hammer ${ }^{17}$ also reported that novices tend to solve problems by manipulating formulae where physics knowledge is organised by surface features as opposed to by physics principles.

Another study illustrated that student success in an introductory undergraduate physics course for naïve learners, is dependent upon student's cognitive understanding and on their epistemological beliefs of physics ${ }^{22}$. Their weekly interviews over 12 weeks looked at students developing conceptions of sound and wave motion. Although the sample size reported is small, an in depth analysis revealed that naïve first year physics undergraduates tend to use different models than experts for understanding sound and wave motion. Their interviews elucidated three 'types' of students: 
Table 2: Example of an Osgood type questionnaire

\begin{tabular}{|l|l|l|l|l|l|l|l|}
\hline $\begin{array}{l}\text { It is good to work with other students } \\
\text { because listening to their points of view, } \\
\text { I can correct my ideas }\end{array}$ & & & & & & & $\begin{array}{l}\text { I prefer not to work with other students } \\
\text { because I might pick up some wrong ideas }\end{array}$ \\
\hline $\begin{array}{l}\text { I think lecturers should avoid teaching } \\
\text { material that they know students will find } \\
\text { difficult. }\end{array}$ & & & & & & & $\begin{array}{l}\text { Lecturers should aim to provide challenges } \\
\text { to students by introducing difficult topics. }\end{array}$ \\
\hline $\begin{array}{l}\text { All I have to do in science is to } \\
\text { memorise what has been taught }\end{array}$ & & & & & & $\begin{array}{l}\text { Understanding science is the key to } \\
\text { scientific study }\end{array}$ \\
\hline
\end{tabular}

1. Some students (without prior physics knowledge) believed that scientific knowledge is conceptual knowledge and developed most of their preinstructional conceptions into acceptable scientific conceptions. Their beliefs about physics knowledge enabled them to choose viable study methods where the physics that they learned in lectures was helpful for understanding the real world.

2. Some students (with prior physics knowledge) believed that physics knowledge is mathematical knowledge and did not develop their conceptions well. Their beliefs that physics problems were simply mathematical formulae and the physics they learned in lectures were not relevant to everyday experiences.

3. Some students viewed physics knowledge to be made up conceptual knowledge where the ultimate goal was to understand formulae to solve problems mathematically. However, no effort was placed on appreciating the conceptual content that was involved. They believed that learning in physics was totally unrelated to their everyday experiences because of the complicated words and meanings.

The progression in student thinking showed that conceptions developed from everyday conceptions to unclear scientific conceptions and finally to scientific conceptions. However, this illustrated that the extent of students' previous physics knowledge did not necessarily influence the development of their physics conceptions.

Although set at secondary school level, it has been reported that epistemological sophistication in physics can be a predictor of conceptual understanding in physics ${ }^{7}$. Stathopoulou and Vosniadou ${ }^{7}$ explored this relationship and all students who showed a deeper understanding of Newtonian dynamics were students with highly sophisticated beliefs. Interestingly, Liu and $\mathrm{Tsai}^{2}$ examined differences between science and non-science majors on their epistemological views. Their results indicated that science majors have less sophisticated beliefs in the theory-laden and cultural aspects of science than non-science majors. They account for this by suggesting that science major students might have been longer involved in an epistemic environment that described scientific knowledge as being objective and universal.
In the Swedish context, Domert, Airey, Linder and Kung ${ }^{23}$ analysed undergraduate and postgraduate students' epistemological beliefs in learning physics equations. They found that advanced physics students felt the need to understand the underlying physics concepts to be more important than those at the earlier stages of their studies. The authors suggest that physics students at the early stages of their learning should be encouraged to link equations to everyday life.

The study by Sins, Savelsbergh, van Joolingen and van HoutWolters ${ }^{8}$ explored the relation between students' epistemological understanding of models and modelling and of their cognitive processing (i.e. deep versus surface processing ${ }^{24,25}$ ) on a computer based physics task. They found (and expected) a positive correlation between students' level of epistemological understanding and their deep processing. This is similar to the work reported by Ozkal, Tekkaya, Cakiroglu and Sungar ${ }^{26}$ in that students who believed that knowledge was tentative appeared to use learning strategies that resulted in deeper processing of information. In addition, Scherr and Hammer ${ }^{27}$ argued that the concept of observing students' behaviours in situ in small group physics tutorials can be useful for determining student epistemologies. For instance, "A student may frame a physics problem as an opportunity for sense-making or as an occasion for rote use of formulas". They found that verbal and nonverbal displays reinforce each other and provided evidence for certain student behaviours that indicate a support for epistemological framing.

Tsai $^{28}$ discussed a constructivist internet-based learning environment for students and reported that more advanced graduate students require opportunities to negotiate ideas, reflect and explore epistemological issues. In addition, students with more internet experiences tended to prefer more features of the constructivist internet-based learning environments than those with less internet experiences. He believed that the internet based learning environment can be perceived as an epistemological tool (as opposed to a cognitive tool) where learners can "develop evaluative standards to judge the merits of information and knowledge, thus exploring some epistemological issues." 
What the above studies tend to suggest is that a consideration of epistemological beliefs and attitudes is important in the physical sciences - both for educational practice and research.

\section{Interventions}

There is a general consensus in the literature that encouraging students through the intellectual and epistemological framework is a desirable aim of higher education $^{29,30}$. Indeed, it is known that sophisticated epistemological beliefs exert a positive influence on students learning strategies and learning outcomes ${ }^{31,32}$.

\section{In the chemistry laboratory:}

Whilst not explicitly related to epistemological and intellectual development, the research of Kelly and Finlayson ${ }^{33}$ has shown that a problem based learning approach in the chemistry laboratory is more conducive to learning and understanding chemistry when compared to a traditional approach. They researched students' attitudes to learning in a problem based laboratory (where the procedure is student generated) as opposed to the traditional expository laboratory. It may be argued that this technique would encourage intellectual growth, as reported by the case of MacKenzie, Johnstone and Brown ${ }^{34}$ in the context of medical education. Their results showed that students undertaking the new problem based learning curriculum demonstrated a more critical, self directed approach to learning and argued that the same can be embedded within science curricula.

Scientific argumentation - web and individual text based: Embedding skills of scientific argumentation ${ }^{35}$ within an introductory physics course has been shown to encourage students to develop more scientific criteria in discussions, in addition to increasing success and conceptual understanding of physics problems ${ }^{21}$. The study was conducted on an online web environment ( $n=88$ undergraduates); this being the vehicle for student discussions, in addition to documenting and coding responses for analysis. Both groups completed online questionnaires on the scientific disposition to argue and an epistemic belief survey and were equally divided into groups. The treatment group received additional online skills in scientific argumentation. The intervention was found to have positive effects in terms of the number of thought experiments, alternative views and qualities of scientific arguments. Although students' willingness to engage in argumentation can vary, the authors argue that it is an important part of the socially constructed nature of scientific enquiry.

The work conducted by Mason, Gava and Boldrin ${ }^{36}$ with pupils in Italy, investigated two types of instructional texts in light, vision and colour: (1) an ordinary expository text whose function was to give new information and (2) a "refutational text that not only gave new, correct information but also explicitly stated and refuted alternative conceptions by presenting the scientific conceptions as viable alternatives". They found that the refutational text facilitated students understanding of new concepts and situational interest.

Overall, epistemological beliefs and exposure to the criteria for sound scientific argument can affect learning of physics concepts - an increasingly important area since research has reported that students may complete physics courses without a proper conceptual understanding of physics ${ }^{37}$.

Historical perspectives of chemistry:

Using written reports and classroom discussions, Niaz ${ }^{38}$ has shown that when students are given the opportunity to reflect and debate various chemistry topics (such as the various models of the atom), understandings of the nature of science can be enhanced (see also the exploratory work of Ibrahim, Buffler and Luben ${ }^{20}$. Niaz also concluded that the interaction among participants facilitated the progressive transitions in students' understandings of the nature of science.

Course type and environment:

Tolhurst ${ }^{39}$ conducted a study to examine how epistemological beliefs may be affected by the implementation of a new course structure. It was found that students were more actively engaged in their learning and positive changes in epistemological beliefs were generated. In addition, students with sophisticated epistemological beliefs attained better results in the end of year examination. More recently, other work by Baily and Finkelstein ${ }^{40,41}$ has demonstrated how students evolve in their thinking as they moved from classical physics to quantum physics. It was found that student perspectives change when making the transition between classical physics (realism, where all physical quantities within that system can be specified simultaneously) and quantum mechanics.

\section{Summary}

In order to inform learning and teaching practices, departments may wish to document and analyse students' epistemological and intellectual development during a degree course $^{42}$ (or before and after an intervention). In turn, the results of such research might further influence the way departments support learning and teaching, and in particular for future student cohorts. Much of the research described above shows that when it comes to learning physical science concepts, student epistemologies matter. In designing effective learning environments, researchers suggest that it is important to develop and evaluate curricula that will facilitate the development of sophisticated epistemological beliefs ${ }^{7}$. 


\section{Appendix - Questionnaires}

As the Perry scheme is relatively complicated, various simplifications ${ }^{15,42,43}$ have been offered, mainly as a means of simplifying measurement and presentation. Various attempts in the literature have been made to convert the epistemological framework into a questionnaire, some of which are listed below:

(1) Example of an Osgood type questionnaire (Table 2)

(2) Evaluation of Teaching, Higher Education Academy Physical Sciences Practice Guide ${ }^{42}$

(3) Views on the nature of science instrument ${ }^{44}$

(4) Student submission of weekly reports ${ }^{18}$

(5) Views About Science Survey (VASS) ${ }^{45}$

\section{References}

1. Hofer, B.K. and Pintrich, P.R. (1997) The Development of Epistemological Theories: Beliefs about Knowledge and Knowing and Their Relation to Learning. Review of Educational Research, 67 (1), 88-140.

2. Liu, S.-Y. and Tsai, C.-C. (2008) Differences in the Scientific Epistemological Views of Undergraduate Students. International Journal of Science Education, $\mathbf{3 0}$ (8), 1055-1073.

3. Elby, A. (2009) Defining Personal Epistemology: A Response to Hofer and Pintrich (1997) and Sandoval (2005). The Journal of the Learning Sciences, 18138 149.

4. Richter, T. and Schmid, S. (2009) Epistemological beliefs and epistemic strategies on self-regulated learning. Metacognition Learning, DOI. 10.1007/s11409-009-90384.

5. Sinatra, G.M. and Pintrich, P.R. (2003) eds. Intentional Conceptual Change. Lawrence Erlbaum Associates: Mahwah, New Jersey.

6. Bell, P. and Linn, M.C. (2004) Beliefs About Science: How Does Science Instruction Contribute?, in Personal Epistemology: The Psychology of Beliefs About Knowledge and Knowing, B.K. Hofer and P.R. Pintrich, Editors, Lawrence Erlbaum Associates: London. p. 321 346 .

7. Stathopoulou, C. and Vosniadou, S. (2007) Exploring the Relationship Between Physics-Related Epistemological Beliefs and Physics Understanding. Contemporary Educational Psychology, 32 255-281.

8. Sins, P.H.M., Savelsbergh, E.R., van Joolingen, W.R., and van Hout-Wolters, B.H.A.M. (2009) The Relation between Students' Epistemological Understanding of Computer Models and their Cognitive Processing on a Modelling Task. International Journal of Science Education, 31 (9), 1205-1229.

9. Moore, B., Perry Network: Cumulative Bibliography and Copy Service Catalog for the Perry Scheme of Intellectual and Ethical Development. 1999, Perry Network: Olympia.

10. Perry, W.G.J. (1999) Forms of Ethical and Intellectual Development in the College Years: A Scheme, San Francisco: Jossey-Bass Publishers.
11. Bhattacharyya, G. (2008) Who am I? What am I doing here? Professional identity and the epistemic development of organic chemists. Chemistry Education Research and Practice, 9 84-92.

12. Berg, C.A.R. (2005) Factors Related to Observed Attitude Change toward Learning Chemistry among University Students. Chemistry Education Research and Practice, 6 (1), 1-18.

13. King, P.M. and Kitchener, K.S. (1994) Developing Reflective Judgment: Understanding and promoting intellectual growth and critical thinking in adolescent and adults, San Francisco, CA: Jossey-Bass.

14. Belenky, M.F., Clinchy, B.M., Goldberger, N.R., and Tarkle, J.M. (1997) Women's Way of Knowing: the development of self, voice, and mind, 10th Anniversary edNew York: Basic Books.

15. Kuhn, D., Cheney, R., and Weinstock, M. (2000) The Development of Epistemological Understanding. Cognitive Development, 15 (309-328).

16. Baxter-Magolda, M. (2001) A Constructivist Revision of the Measure of Epistemological Reflection. Journal of College Student Development, (Nov/Dec).

17. Hammer, D. (1994) Epistemological Beliefs in Introductory Physics. Cognition and Instruction, 12 (2), 151-183.

18. May, D.B. and Etkina, E. (2002) College Physics Students' Epistemological Self-Reflection and its Relationship to Conceptual Learning. American Journal of Physics, 70 (12), 1249-1258.

19. Lising, L. and Elby, A. (2005) The Impact of Epistemology on Learning: A case study from introductory physics. American Journal of Physics, 73 (4), 372-382.

20. Ibrahim, B., Buffler, A., and Lubben, F. (2009) Profiles of Freshman Physics Students' Views on the Nature of Science. Journal of Research in Science Teaching, $\mathbf{4 6}$ (3), 248-264

21. Nussbaum, E.M., Sinatra, G.M., and Poliquin, A. (2008) Role of Epistemic Beliefs and Scientific Argumentation in Science Learning. International Journal of Science Education, 30 (15), 1977-1999.

22. Chu, H.-E., Treagust, D.T., and Chandrasegaran, A.L. (2008) Naïve Students' Conceptual Development and Beliefs: The Need for Multiple Analyses to Determine what Contributes to Student Success in a University Introductory Physics Course. Research in Science Education, 38 111-125.

23. Domert, D., Airey, J., Linder, C., and Kung, R.L. (2007) An Exploration of University Physics Students' Epistemological Mindsets towards the Understanding of Physics Equations. Nordina, 1 15-28.

24. Marton, F. and Säljö, R. (1997) Approaches to Learning, in The Experience of Learning. Implications for teaching and learning in higher education, F. Marton, D. Hounsell, and N. Entwistle, Editors, Scottish Academic Press: Edinburgh. p. 39-59.

25. Entwistle, N.J. (1981) Styles of Learning and Teaching, London: Wiley David Fulton publishers. 
26. Ozkal, K., Tekkaya, C., Cakiroglu, J., and Sungar, S. (2009) A Conceptual Model of Relationships among Constructivist Learning Environment Perceptions, Epistemological Beliefs and Learning Approaches. Learning and Individual Differences, 19 71-79.

27. Scherr, R.E. and Hammer, D. (2009) Student Behaviour and Epistemological Framing: Examples from Collaborative Active-Learning Activities in Physics. Cognition and Instruction, 27 (2), 147-174.

28. Tsai, C.-C. (2008) The preferences toward constructivist Internet-based learning environments among university students in Taiwan. Computers in Human Behaviour, 24 16-31.

29. Kloss, R.J. (1994) A Nudge is best: Helping students through the Perry Scheme of Intellectual Development. College Teaching, 42 (4), 151-158.

30. Marra, R. and Palmer, B. (2004) Encouraging Intellectual Growth: Senior College Student Profiles. Journal of Adult Development, 11 (2), 111-122.

31. Mason, L. and Boscolo, P. (2004) Role of Epistemological Understanding and Interest in Interpreting a Controversy and in Topic-Specific Belief Change. Contemporary Educational Psychology, 29 103-128.

32. Schommer, M. (1993) Epistemological Development and Academic Performance among Secondary Students. Journal of Educational Psychology, 85 (3), 406-411.

33. Kelly, O. and Finlayson, O. (2009) A Hurdle too High? Students' experience of a PBL laboratory module. Chemistry Education Research and Practice, 10 42-52.

34. MacKenzie, A.M., Johnstone, A.H., and Brown, R.I.F. (2003) Learning from Problem Based Learning. University Chemistry Education, 7 13-26.

35. Nussbaum, E.M. Criteria for a Good Scientific Argument. 2008 [cited 01 June 2009]; Available from: http:// faculty.unlv.edu/nussbaum/epy451_files/criteria.htm.

36. Mason, L., Gava, M., and Boldrin, A. (2008) On Warm Conceptual Change: The Interplay of Text, Epistemological Beliefs, and Topic Interest. Journal of Educational Psychology, 100 (2), 291-309.

37. Benckert, S. and Pettersson, S. (2008) Learning Physics in Small-Group Discussions - Three Examples. Eurasia Journal of Mathematics, Science \& Technology Education, 4 (2), 121-134.

38. Niaz, M. (2009) Progressive Transitions in Chemistry Teachers' Understanding of Nature of Science Based on Historical Controversies. Science \& Education, 18 43-65.

39. Tolhurst, D. (2007) The Influence on Learning Environments on Students' Epistemological Beliefs and Learning Outcomes. Teaching in Higher Education, 12 (2), 219-233.

40. Baily, C. and Finkelstein, N.D. Student Perspectives in Quantum Physics. in Physics Education Research Conference (PERC). 2008. Edmonton, Alberta (Canada).

41. Baily, C. and Finkelstein, N.D. (2009) Development of Quantum Perspectives in Modern Physics. Physical Review Special Topics - Physics Education Research, $\mathbf{5}$ (1), 010106-1 - 010106-8.
42. Johnstone, A. (2005) Evaluation of Teaching: A Physical Sciences Practice Guide, Hull: Higher Education Academy: Physical Sciences Centre.

43. Finster, D.C. (1989) Developmental instruction: Part 1. Perry's Model of Intellectual Development. Journal of Chemical Education, 66 (8), 659-661.

44. Lederman, N.G., Adb-El-Khalick, F., Bell, R.L., and Schwartz, R.S. (2002) Views on Nature of Science Questionnaire: Toward Valid and Meaningful Assessment of Learners' Conceptions of Nature of Science. Journal of Research in Science Teaching, 39 (6), 497-521.

45. Halloun, I. and Hestenes, D. (1998) Interpreting VASS Dimensions and Profiles for Physics Students. Science \& Education, 7 553-577. 